\title{
Prevention of Maternal Mortality by Training the Birth Attendants of Church- Based Maternity Homes in Akwa-Ibom State
}

\author{
Edem J. Udoma', Samuel M. Itina ${ }^{2}$, Asuquo D Ekanem ${ }^{\prime}$ and Margaret M. Mboho ${ }^{2}$ \\ 'Department of Obstetrics \& Gynaecology, College of Medical Sciences, University of Calabar and ${ }^{2}$ Saint Lukes \\ Hospital, Anua-Uyo, Akwa Ibom State, Nigeria.
}

\begin{abstract}
Context: A significant proportion of births in Nigeria still occur in spiritual churches and homes of traditional birth attendants. Recent studies have revealed a lot of complicated cases of obstructed labour from spiritual churches.

Objectives: To examine the outcome of training and integration of the spiritual church based midwives on maternal morbidity and mortality.

Design and Setting: A pre-and post-time series experimental study was conducted in five local governments of Akwa Ibom state in Nigeria.

Subjects and Methods: Fourteen churchbased clinics were visited between $1^{\text {st }}$ January 2001 and $31^{\text {st }}$ January 2003. Structural interview and focus group discussion were used to collect data on their midwives knowledge of 20 risk factors in pregnancy, labour and puerperium and practice of referral. Formal teaching also was given for one month on midwifery practices. After the training, they were asked to keep proper records of all pregnant women. High risk cases were referred to Anua General Hospital in Akwa Ibom State. The records were checked at six and twelve month's interval.

Results: Before the training only 10 (23.8\%) midwives could recognise up to half of the listed risk factors. The knowledge and practice of referral increased significantly after training $(p<0.00001$ and $p=0.0000021$ respectively). There were no maternal deaths.

Conclusion: We recommend that the midwives attending births in churches and other faith-based healing homes be trained and their practices integrated into the orthodox health care delivery system with regular checks by the health ministry.
\end{abstract}

\section{Introduction}

Maternal mortality has attracted increasing attention and interest in the last decade. It has been estimated that almost 600,000 women die annually from complications of pregnancy and that over 40,000 of these deaths occur in Nigeria'. Unless effective programmes are developed, one out of thirteen women in Nigeria will continue to die as a result of pregnancyrelated causes'. Upgrading health facilities, improving the skills of personnel at the first referral level to manage obstetrics emergencies and addressing the problems of inaccessibility have been identified as promising approaches to reducing maternal morbidity and mortality ${ }^{2}$. Local initiatives have been established in some developing countries including Nigeria to clarify problems and develop strategies to effectively address them. However, the extent to which obstetric care succeeds in achieving its goal is a function inter-alia, of the cultural, socio economic and environmental conditions under which the care is provided ${ }^{3}$. A significant proportion of all births in Nigeria still occur in the homes of traditional birth attendants and spiritual churches ${ }^{4}$. Unless this situation is addressed maternal mortality will continue to be on the increase in our environment. Efforts were earlier made to train the traditional birth attendant as well as integrating them into orthodox health care systems. While the outcome was still being assessed, the obstetric practices in the spiritual churches came. The antenatal, intranatal and postnatal care that occurs within the spiritual church premises that is based on the principles of faith, prophecies and prayers is termed spiritual church-based obstetric practices in this study. Their clinics are also referred to as spiritual church- based clinics. Recent, studies have shown that most of the maternal mortalities came from the spiritual church- based clinics ${ }^{4}$. It may be difficult to dissuade our women from attending these clinics since their practices are based on faith and prophecies. Non conformity to the tenets of faith may bring severe penalties to their members ${ }^{3}$. Earlier studies had shown that these spiritual church clinics charged nothing from their clients ${ }^{6}$. This may be the reason for the high patronage by our pregnant women. Suggestions were earlier made to train these spiritual church- based midwives as well as integrating their clinics to orthodox health care system ${ }^{6}$, as a way of reducing maternal morbidity and mortality arising from them. To the best of the knowledge of the authors such programmes and the outcome have not been reported in our environment. This study examined the extent to which the training of the spiritual church-based midwives and their integration into the orthodox health care services could reduce maternal morbidity and mortality.

Correspondence: Dr E. J. Udoma, Department of

Obstetrics and Gynaecology, College of Medical Sciences,

University of Calabar.

E-mail: e udoma@yahoo.com 


\section{Materials and Methods}

The study was conducted in five local government areas of Akwa Ibom state in the south south zone of Nigeria. Fourteen spiritual church-based clinics with interest in obstetrics care, identified by the public health coordinators were visited between $1^{\text {st }}$ February 2001 and $31^{\text {st }}$ January 2002 . The church leaders were invited to a one day seminar on safe motherhood as a way of creating awareness and seeking their co-operation. At the seminar the high maternal mortality rate in the state, the causes and the various ways of preventing these deaths were discussed. The role of spiritual churches in these mortalities was emphasized. At the end of the seminar, the need to train their midwives in obstetric care was presented to them. They were also informed that the team would not only train their midwives, but would also examine their patients in their various clinics as well as giving health talk on safe motherhood. Again haematinics, anti helminthics and malaria prophylaxis would be given free of charge to their patients. This was accepted by the spiritual church leaders. Forty-two midwives from 14 spiritual church- based clinics were invited to one month training in obstetric care. A pre/post time series experimental test was carried out. Subjects were interviewed to identify what they considered abnormalities in pregnancy, labour and puerperium, identify harmful practices and the practice of referral (in terms of number of patients referred in the last three months, reasons for referral, problems encountered during referral etc.)

Focus group discussion was also used to explore ideas and gather detailed information from the subjects. After these they were given formal teaching on harmful midwifery practices, twenty risk factors in pregnancy, labour and puerperium and how to recognize them when and how to refer clients. The teaching modules were translated into local languages for better understanding by the subjects. Role play was also utilized during teaching. Data in the knowledge of risk factors were collected before teaching, at the end of teaching, six months and one year after teaching. Interview schedule containing a check list on a rating scale developed by the authors was used. This had been pre-tested on 10 spiritual church midwives with test reliability coefficient of 0.83 at 2 weeks interval. At the end of teaching, they were asked to record the number of pregnant women, their various centres, number of deliveries attended to, and their outcome, number of referrals as well as reasons for referrals. The records were checked at, six and twelfth months' interval. The antenatal clinic days of each spiritual church based clinics were identified and an itinerary drawn up to visit the church once a month. At the visit, the pregnant women were examined and given drugs free of charge. Also high risk pregnancies identified by the spiritual church midwives, were asked to be referred to Anua
General Hospital a centre specifically identified as referral centre for the study. The hospital records in this centre were also checked to confirm the referrals made by the various spiritual churches during the period. Data were analysed using simple proportion as well as descriptive statistics. Recognition of less than six of the i...iti risk factors (less than 30 percent) and their chinical indicators was regarded as poor knowledge, 6 to $1:(30$ to $69 \%)$ fair knowledge and 14 and above (70 percent and above), good knowledge. Chi-Square was used to test for significance.

\section{Results}

There were 42 midwives in 14 spiritual church-based clinics. Socio demographic data revealed that they were women aged between 25 to 68 years with a mean age of 47 years. They were all married with $10(23.8 \%)$ being wives of pastors in charged of the churches. Twenty eight $(66.7 \%)$ had no formal education, $9(21.4 \%)$ with primary education and $3(7.1 \%)$ with secondary education. Their duration of practice showed that $4(9.5 \%)$ had practiced for less than 5 years, $8(19.0 \%)$ had practiced for 5 to 10 years, $17(40.5 \%)$ for 10 to 20 years, and $13(31 \%)$ for over 20 years.

Pre-teaching data on recognition and knowledge of risk factors as well as practice of referral showed that, $10(23.8 \%)$ could only recognise up to half of the listed 20 risk factors in pregnancy, labour and puerperium. In terms of referral, only $9(21.4 \%)$ referred cases; the rest used prayers and holy water as their method of treatment. The common risk factors recognised by 15 $(35 \%)$ of the midwives were bleeding in pregnancy, convulsion in pregnancy, jaundice in pregnancy, vaginal discharge. Other recognised risk factors included fever and chills in labour and retained placenta. The least recognised risk factors were pale palpabral conjunctiva with easy fatigue (anaemia) and sudden ceasation of hitherto strong uterine contractions with fetal part easily palpable (uterine rupture) .In terms of recognition of referral for risk factors, only $9(21.4 \%)$ recognized up to $50 \%$ of the factors that required referral especially bleeding during pregnancy and delivery, retained placenta, persistent headache and convulsions .No subject recognized the need to refer a woman who hitherto had strong uterine contractions that suddenly ceased. Twenty eight $(66.7 \%)$ subjects claimed they could handle any type of complications with prayers and faith in God and therefore requires no referral. The actual referral prior to the training was done by two spiritual health clinics (Table1).

Comparison of pre and post teaching knowledge revealed that $33(78.6 \%$ ) had poor knowledge, while $9(21.8 \%)$ had good knowledge prior to teaching. Whereas $6(14.3 \%)$ had poor knowledge, $36(85.7 \%)$ had good knowledge six months after teaching. Referral for risk factors also increased to $26(61.9 \%)$ six months after 
Table 1:

Knowledge of Risk Factors and Practice of Referrals in Pre-Teaching Group

\begin{tabular}{|c|c|c|c|c|}
\hline Risk Factors & & of Risk Factors & & ce of Referral \\
\hline & & $\%$ & & $\%$ \\
\hline A. PREGNANCY FACTORS & & & & \\
\hline 1. Bleeding with or without pain & 27 & 65.3 & 5 & 11.9 \\
\hline 2. Swollen, hands, face, ankles, headache & 8 & 19.0 & 3 & 7.1 \\
\hline 3. Convulsion & 10 & 23.8 & 3 & 7.1 \\
\hline 4. Abnormal Lie & 6 & 14.3 & 1 & 2.4 \\
\hline 5. Jaundice & 15 & 35.7 & 2 & 4.8 \\
\hline 6. History of previous APH, PPH \& C/S & 5 & 11.9 & 1 & 2.4 \\
\hline 7. Persistent headache with dizziness and blurred vision & 11 & 26.2 & 1 & 2.4 \\
\hline 8. Pale conjunctiva with fatigability & 2 & 4.8 & 1 & 2.4 \\
\hline 9. Low maternal age & 2 & 4.8 & 1 & 2.4 \\
\hline B.LABOUR FACTORS & & & & \\
\hline 1.Profuse bleeding & 25 & 59.5 & 7 & 16.7 \\
\hline 2.Convulsion & 17 & 40.5 & 6 & 11.3 \\
\hline 3.Fever, chills and vaginal discharge & 12 & 28.6 & 4 & 9.5 \\
\hline 4. Poor progress (dawn to dusk or & & & & \\
\hline Dusk to dawn) despite strong contractions & 7 & 16.7 & 5 & 11.9 \\
\hline 5.Abnormal lie & 8 & 19.0 & 3 & 7.1 \\
\hline $\begin{array}{l}\text { 6. Sudden ceasation of strong } \\
\text { contraction with baby felt clearly on }\end{array}$ & & & & \\
\hline palpation of the abdomen (uterine rupture) & 3 & 7.21 & 1 & 2.4 \\
\hline 7.Baby does not come out after & & & & \\
\hline $30 \mathrm{mins}$ of second stage of labour & 3 & 7.1 & 1 & 2.4 \\
\hline C.PUERPERIUM FACTORS & & & & \\
\hline 1.Profuse bleeding & 16 & 35.1 & 5 & 11.9 \\
\hline 2. Retained placenta & 36 & 85.7 & 4 & 9.5 \\
\hline 3 Foul smelling vaginal discharge with fever & 17 & 40.5 & 3 & 7.1 \\
\hline Convulsion & & 28.6 & 1 & 2.4 \\
\hline
\end{tabular}

Table 2

Knowledge of Risk Factors and Practice of Referrals, Before and Six Months after the Training $(\mathrm{N}=42)$

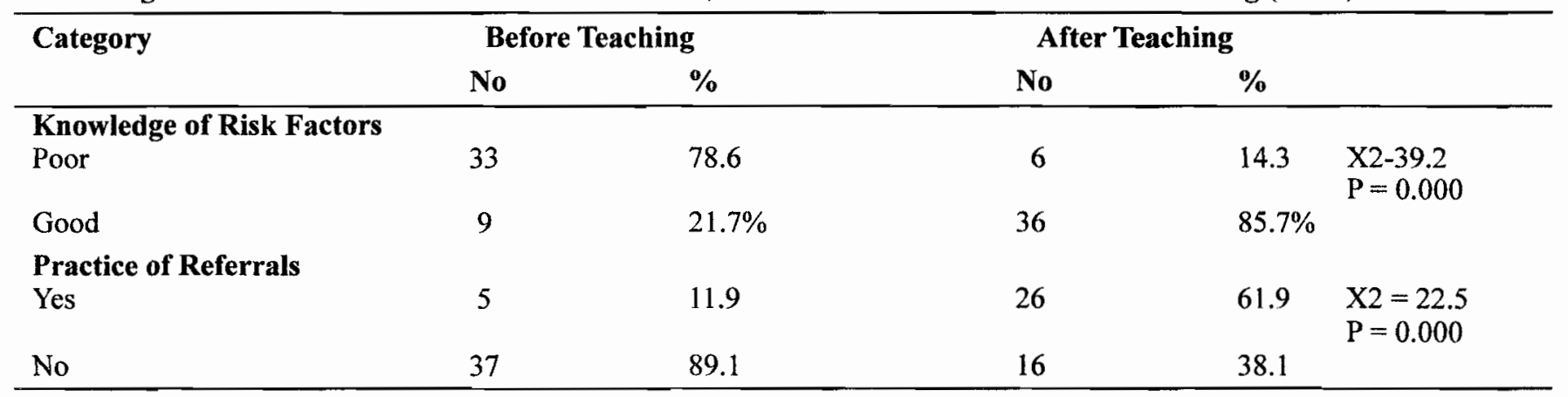

teaching and progressively increased to $38(90.5 \%)$ over the period of one year (Table2). This was confirmed with the hospital records of the referral centre. A total of 2098 pregnant women were registered with identification numbers at various spiritual church clinics during the study. Out of these number, 1429 $(88.1 \%)$ had spontaneous vaginal deliveries in the spiritual church-based clinics, 679 were referred to the designated referral centre. Out of these, $405(59.8 \%) \mathrm{had}$ spontaneous vaginal delivery, $226(33.2 \%)$ had instrumental delivery and $48(7.1 \%)$ had caesarean section. There was no maternal death among those registered in the programme during the study.

\section{Discussion}

The study has highlighted the socio-demographic characteristics of the spiritual church- based midwives and their knowledge concerning the risk factors in pregnancy, labour and puerperium. Earlier studies had revealed that their standard of midwifery were comparable to that of the traditional birth attendants. The only difference between them being that while the traditional birth attendants often undergo long period of apprenticeship before they commence their traditional birth attendants work ${ }^{7}$, they are selected through divine calling, hence the associated high maternal mortality in earlier study ${ }^{4}$. 
The study also revealed that majority of the subjects could not recognise the risk factors of pregnancy, labour, puerperium and the need for immediate referral, thereby leaving their clients too late to benefit from medical intervention. Earlier studies had highlighted this important observation '. They are generally reluctant to release cases with complications to conventional health centres, resorting to prayers for management of complications ${ }^{3}$. The possible explanation may be that in Nigeria, difficult labour is usually attributed to supernatural causes ${ }^{8}$, and therefore require divine intervention.

The training significantly increased their knowledge of the risk factors. A similar reported training for the traditional birth attendants had shown an improved knowledge of risk factors ${ }^{5,8.9}$. Referral also increased as reported from various church clinics with a confirmation from hospital records. Although there was no previous documentation concerning maternal mortality in these spiritual church-based clinics, the present study has recorded no maternal deaths from these places. This is probably due to the fact that, there was a constant interaction by the health personnel and the spiritual church midwives every month. Problematic

\section{References}

1. World Health Organisation/UNICEF; Revised 1990 estimates of maternal mortality: A New approach by WHO and UNICEF 1996. WHO/FRH/MSH/96.11; UNICEF/PLN/96.

2. Maine D. Safe Motherhood Programmes: Options and issues. New York Centre for population and Family Health, Columbia University, 1991 .

3. Adetunji J A. Church based obstetrics care in Yoruba community. Soc Sc Med, 1992;35(9): 11711178.

4. Udoma E J, Asuquo E E J, Ekott M I. Maternal mortality from obstructed labour. The role of spiritual churches. Int $J$ Gynecol Obstet, 1999; 67 103- 105.

5. Brendan $M$. Training traditional birth attendants. Postgraduate Doctor, 1989; 11(1): 16-19. cases were shown to them at every visit and those that require referral were promptly referred.

Abolishing the practices of these spiritual churches may be difficult as their practices are based on various sociocultural and economic factors. It is therefore recommended that the spiritual church midwives be trained and their practices integrated into the orthodox health care delivery with regular checks by the health ministry. They should be identified and made to register with the appropriate Health authority with an affiliation to an orthodox health centre as their referral centre with their practices being monitored regularly. Most importantly, they should be a grass root mobilization of the community and a large scale public education to create awareness on the problems of maternal morbidity and mortality, with the need to utilize orthodox maternal services for care during pregnancy and delivery. It is hoped that this will increase the utilization of orthodox health care system with reduction in the patronage of unorthodox health care services and maternal morbidity and mortality.

\section{Acknowledgement:}

The Ford Foundation, Nigeria awarded a Research Grant for the conduct of this study.
6. Udoma E J, John M E, Udosen G E, Udo A E. Obstetrics practices in spiritual churches in South Eastern Nigeria. Mary SlessorJMedSc, 2003; 3(2) 51-56.

7. Alti-Mu Azu. Women as providers and consumers of the traditional birth delivery system. In: MN. Kisseka (ed), Women's Health Issues in Nigeria. Zaria: Tamoza publishing Ltd, 1992; 149-168.

8. John ME, Udoma E J, Udoh MO, Ndebbio T J. Knowledge and practice of traditional birth attendants concerning risks factors in pregnancy, labour and puerperium. Afr J Nursing Midwifery, $2002 ; 4(1) ; 41-5$.

9. Mathews M K, Walley R I, Ward A, Akpanidem M, Williams P, Umoh A. Training TBAS in Nigeria, the Pictorial Method. World Health Forum, 1995; 16:409-416. 